\title{
THE EFFECT OF TEMPERATURE MANAGEMENT DURING CARDIOPULMONARY BYPASS ON NEUROLOGIC AND NEUROPSYCHOLOGIC OUTCOMES IN PATIENTS UNDERGOING CORONARY REVASCULARIZATION
}

Christina T. Mora, $\mathrm{MD}^{\mathrm{a}}$

Martha B. Henson, $\mathrm{MA}^{\mathrm{a}}$

William S. Weintraub, $\mathrm{MD}^{\mathrm{b}}$

John M. Murkin, MD ${ }^{\text {d }}$

Tomas D. Martin, MD ${ }^{\mathrm{c}}$

Joseph M. Craver, $\mathrm{MD}^{\mathrm{c}}$

John Parker Gott, $\mathrm{MD}^{\mathrm{c}}$

Robert A. Guyton, $\mathrm{MD}^{\mathrm{c}}$
Several studies suggest that normothermic ("warm") bypass techniques may improve myocardial outcomes for patients undergoing cardiac operations. Normothermic temperatures during cardiopulmonary bypass may, however, decrease the brain's tolerance to the ischemic insults that accompany all cardiac procedures. To assess the effect of bypass temperature management strategy on central nervous system outcomes in patients undergoing coronary revascularization, 138 patients were randomly assigned to two treatment groups: (1) hypothermia ( $n=70$ ), patients cooled to a temperature less than $28^{\circ} \mathrm{C}$ during cardiopulmonary bypass, or $(2)$ normothermia $(n=68)$, patients actively warmed to a temperature of at least $35^{\circ} \mathrm{C}$. Patients underwent detailed neurologic examination before the operation, on postoperative days 1 to 3 and 7 to 10 , and at approximately 1 month after operation. In addition, a battery of five neuropsychologic tests was administered before operation, on postoperative days 7 to 10, and at the 4- to 6-week follow-up visit. Patients in the normothermic treatment group were older $(65 \pm 10$ vs $61 \pm 11$ years in the hypothermic group), had statistically less likelihood of preexisting cerebrovascular disease, and had higher bypass blood glucose values $(276 \pm 100 \mathrm{mg} / \% \mathrm{vs}$. $152 \pm 66 \mathrm{mg} / \%$ in the hypothermic group). All other patient characteristics and intraoperative variables were similar in the two treatment groups. Seven of 68 patients in the normothermic group were found to have a central neurologic deficit, compared with none of the patients cooled to $28^{\circ} \mathrm{C}(p=$ 0.006). Performance on at least one neuropsychologic test deteriorated in the immediate postoperative period in more than one half of all patients in both treatment groups but returned to preoperative levels approximately 1 month after the operation in most $(85 \%)$. This pattern was not related to bypass temperature management strategy. We conclude that active warming during cardiopulmonary bypass to maintain systemic temperatures $\geq 35^{\circ} \mathrm{C}$ increases the risk of perioperative neurologic deficit in patients undergoing elective coronary revascularization. (J Thorac Cardiovasc Surg 1996;112:514-22) n the early 1950s, Bigelow, Lindsay, and Greenwood $^{1}$ demonstrated that metabolic rate was linked to temperature and postulated that hypother-

From the Divisions of Cardiothoracic Anesthesiology, ${ }^{a}$ Cardiology, ${ }^{\mathrm{b}}$ and Cardiothoracic Surgery, ${ }^{\mathrm{c}}$ Emory University School of Medicine, Atlanta, Ga., and the Department of Anaesthesia, ${ }^{\mathrm{d}}$ University of Western Ontario, London, Ontario, Canada.

Received for publication Sept. 29, 1995; revisions requested Dec. 19, 1995; revisions received Jan. 22, 1996; accepted for publication Jan 25, 1996.

Address for reprints: Christina T. Mora, MD, Department of Anesthesia, Stanford University Hospital, Stanford, CA 94305-5115.

Copyright (C) 1996 by Mosby-Year Book, Inc.

0022-5223/96 \$5.00+0 $\quad \mathbf{1 2 / 1 / 7 2 3 2 1}$ mia could facilitate cardiac operations. Hypothermia has since become the mainstay of organ protection-particularly for the heart and brain--during cardiopulmonary bypass (CPB). ${ }^{2}$ Studies in the early 1990 s, however, suggested that normothermic cardioplegia might enhance myocardial protection during cardiac operations, and "warm" techniques have since been widely adopted. ${ }^{3-10}$

To date, several studies have assessed the effect of normothermic cardioplegia and CPB on myocardial and neurologic outcomes in patients undergoing coronary revascularization. $6,8,10,11$ Most investigators agree that normothermic cardioplegia is an acceptable alternative myocardial protection strategy, but they differ with respect to findings of 
neurologic outcomes associated with normothermic techniques. Martin and associates ${ }^{8}$ demonstrated a substantially increased risk of neurologic dysfunction in patients maintained at normothermic temperatures during $C P B$, whereas the Warm Heart Investigators (WHI) ${ }^{10}$ and McLean and coworkers ${ }^{11}$ reported no increased risk of adverse neurologic $^{10,11}$ or neuropsychologic ${ }^{11}$ outcomes.

Because even small fluctuations in brain temperature substantially affect the response to cerebral hypoxia, it is important to discriminate among various $\mathrm{CPB}$ temperature management strategies when considering the effect of normothermic versus hypothermic techniques on various outcomes. Several animal studies suggest that even small increases in cerebral temperature $\left(1^{\circ}\right.$ to $\left.2^{\circ} \mathrm{C}\right)$ exacerbate ischemic neuronal injury. ${ }^{12-19}$ Cerebral temperatures of $38^{\circ}$ to $39^{\circ} \mathrm{C}$ are associated with an increase in excitotoxic neurotransmitter release during cerebral hypoxia and with a delay in equilibration of intracellular high-energy phosphate metabolism. ${ }^{17,19}$ In contrast, mild hypothermia (temperature reduction of $2^{\circ}$ to $4^{\circ} \mathrm{C}$ ) has been shown to ameliorate cerebral ischemic damage. ${ }^{12-14}$ Varying CPB techniques that include seemingly minor differences in target temperatures may thus result in profoundly different neurologic outcomes and quality of life after cardiac operations.

This study was designed to determine whether patients undergoing coronary revascularization who are actively warmed during extracorporeal circulation to maintain systemic temperatures between $35^{\circ}$ to $37^{\circ} \mathrm{C}$ have a higher incidence of perioperative central nervous system sequelae than those who are treated with hypothermic perfusion. Central nervous system morbidity was determined by both neurologic and neuropsychologic outcomes.

\section{Patients and methods}

Design. Of 1001 patients randomly assigned to undergo either hypothermic or normothermic cardiac operations, a subset of 138 patients scheduled for coronary revascularization procedures was randomly assigned to receive either intermittent cold oxygenated crystalloid cardioplegic solution during $\mathrm{CPB}$ with systemic hypothermia $\left(\leq 28^{\circ} \mathrm{C}\right)(n=70)$ or continuous normothermic blood retrograde cardioplegic solution during normothermic $\left(\geq 35^{\circ} \mathrm{C}\right) \mathrm{CPB}(n=68)$. Patients scheduled for concomitant procedures (vascular surgery, valvular procedures, aneurysmectomy, repair of atrial or septal defects, or placement of internal defibrillators) or admitted to the operating room directly from the cardiac catheterization laboratory were excluded. The study protocol was approved by the Emory University Human Investigations
Committee, and informed consent was obtained from all participating patients. Treatments were randomly assigned before operation by means of computer-generated random-numbers. Investigators performing the preoperative and postoperative assessments and the statistical analyses after completion of study were unaware of treatment group assignment. Only the pharmacist responsible for preparing the cardioplegic solutions (who opened a sealed envelope to ascertain study group assignment) and treating clinicians in the operating room and intensive care unit were aware of group assignment.

Anesthesia techniques. Patients were medicated before the procedure with intramuscular morphine sulfate $(0.07$ to $0.15 \mathrm{mg} / \mathrm{kg}$ ) and either intramuscular midazolam hydrochloride $(0.02$ to $0.05 \mathrm{mg} / \mathrm{kg}$ ) or oral diazepam $(0.10$ to $0.15 \mathrm{mg} / \mathrm{kg}$ ). Anesthesia was induced with either intravenous fentanyl citrate $(10$ to $25 \mu \mathrm{g} / \mathrm{kg})$ or intravenous sufentanil citrate ( 2 to $5 \mu \mathrm{g} / \mathrm{kg}$ ) and supplemental intravenous doses of midazolam $(0.05$ to $0.10 \mathrm{mg} / \mathrm{kg})$. Muscle relaxation was established and maintained with intermittent intravenous doses of pancuronium or vecuronium $(0.1$ to $0.4 \mathrm{mg} / \mathrm{kg})$ throughout the operative period. During $\mathrm{CPB}$, anesthesia was maintained with supplemental doses of fentanyl, sufentanil, or isoflurane $(0.25 \%$ to $1.0 \%)$, or with a propofol infusion (50 to $150 \mu \mathrm{g} \cdot \mathrm{kg}^{-1} \cdot \mathrm{min}^{-1}$ ).

CPB and cardioplegic techniques. The myocardial protection techniques used in this study have been described in detail elsewhere. ${ }^{8}$ Briefly, in the normothermic group, high-potassium (100 mmol/L potassium chloride) blood cardioplegic solution ( $4: 1$ blood to crystalloid solution, final potassium concentration $24 \mathrm{mEq} / \mathrm{L}$, temperature $\geq 35^{\circ} \mathrm{C}$ ) was infused in the aortic root at a rate of 100 to $350 \mathrm{ml} / \mathrm{min}$ and a pressure of 100 to $300 \mathrm{~mm} \mathrm{Hg}$ to achieve diastolic arrest. Subsequently, low-potassium (30 mmol/L potassium chloride) solution (temperature $\geq 35^{\circ} \mathrm{C}$ ) was administered continuously through a transatrial retrograde coronary sinus catheter (Gundry Retroplegia Cannula; DLP, Inc., Grand Rapids, Mich.). The remaining cardioplegic components (as described by Fremes) included $12 \mathrm{mmol} / \mathrm{L}$ trihydroxymethylaminomethane, $9 \mathrm{mmol} / \mathrm{L}$ magnesium sulfate, $250 \mathrm{mmol} / \mathrm{L}$ dextrose, and $20 \mathrm{mmol} / \mathrm{L}$ citrate-phosphate-dextrose-adenine. Coronary sinus pressures were maintained at approximately $40 \mathrm{~mm}$ $\mathrm{Hg}$, coronary sinus flow rates ranged from 40 to 250 $\mathrm{ml} / \mathrm{min}$, and a negative-pressure vent was placed in the aortic root to permit return of cardioplegic solution. If necessary, retrograde infusion was interrupted briefly ( $<10$ minutes) to permit optimal visualization of distal coronary anastomoses. Most proximal anastomoses were performed during partial occlusion of the aorta. Systemic normothermia (bladder temperature $\geq 35^{\circ} \mathrm{C}$ ) was maintained during CPB by means of a water-bath heater-cooler (Hematherm Sub-Zero, Cincinnati, Ohio), with bath temperature kept at a maximum of $40^{\circ} \mathrm{C}$.

In the hypothermic group, myocardial protection was achieved with intermittent cold oxygenated crystalloid cardioplegic solution (temperature $\leq 8^{\circ} \mathrm{C}$ ) and externally applied cold crystalloid ice-slush solution. The cardioplegic solution included $1000 \mathrm{ml}$ Plasma-Lyte A (Baxter Healthcare Corp., Deerfield, Ill.), $25 \mathrm{mEq}$ potassium chloride, $3 \mathrm{ml} 50 \%$ dextrose, $20 \mathrm{mEq}$ sodium bicarbonate, 
and $8.6 \mathrm{ml} 10 \%$ calcium gluconate. Initial myocardial arrest was achieved by infusing $1000 \mathrm{ml}$ cardioplegic solution into the root of the crossclamped aorta at 150 to $450 \mathrm{ml} / \mathrm{min}$. Cardioplegic solution was intermittently administered through the coronary sinus aortic root, saphenous vein grafts, or both to maintain myocardial arrest and was reinfused every 15 to 20 minutes or if there was any evidence of myocardial activity. Distal anastomoses were placed during aortic occlusion and myocardial arrest; most proximal anastomoses were performed during partial occlusion of the aorta. Systemic hypothermia (bladder temperature $\leq 28^{\circ} \mathrm{C}$ ) was maintained throughout $\mathrm{CPB}$ with the use of a water-bath heater-cooler. Bladder temperature in both groups was monitored by means of a Foley catheter with temperature probe (Bard Urotrack Plus Foley; Bard Urological, Covington, Ga.).

CPB techniques in both treatment groups included roller pumps (Cinco Heart-Lung Machines, Wakefield, Mass.), membrane oxygenators (Cobe Excel Adult Membrane Lung; Cobe Cardiovascular, Inc., Arvada, Colo.), arterial line filters $(30 \mu \mathrm{m})$, and single aortic and atrial cannulation methods. Plasma-Lyte A was circulated through a $5 \mathrm{~mm}$ prebypass filter to prime the pump circuit. Nonpulsatile pump flows were maintained at 2.2 to 2.5 $\mathrm{L} \cdot \mathrm{min}^{-1} \cdot \mathrm{m}^{-2}$ when the temperature was at least $32^{\circ} \mathrm{C}$ and as low as $1.8 \mathrm{~L} \cdot \mathrm{min}^{-1} \cdot \mathrm{m}^{-2}$ when the temperature was less than $32^{\circ} \mathrm{C}$. Mean arterial pressure was maintained between 40 and $70 \mathrm{~mm} \mathrm{Hg}$; if necessary, vasoconstrictive drugs (phenylephrine, norepinephrine) were used to maintain perfusion pressure. Hypertension (mean arterial pressure $>80 \mathrm{~mm} \mathrm{Hg}$ ) during $\mathrm{CPB}$ was treated by administration of anesthetic drugs (see Anesthesia Techniques) or sodium nitroprusside. Moderate hemodilution (hematocrit $18 \%$ to $25 \%$ ) and alpha-stat acid-base management techniques were used. Oxygen inflow was adjusted to maintain the oxygen tension between 250 to 350 $\mathrm{mm} \mathrm{Hg}$ and the systemic venous oxygen saturation at $70 \%$ or more during CPB. Anticoagulation was achieved with an initial $4.0 \mathrm{mg} / \mathrm{kg}$ dose of heparin; additional doses were administered to maintain the activated clotting time higher than 300 seconds (Hemochron 80; International Technidyne Corporation, Edison, N.J.) or heparin levels higher than 3 (Hemostasis Management System; Medtronic Cardiopulmonary, Anaheim, Calif.).

The study protocol did not mandate any aspect of postoperative care. Decisions regarding patient care in the intensive care unit were made by the attending surgeon (who was aware of treatment group) and the intensive care unit physicians and other staff members (who were unaware of treatment assignment).

Neurologic and neuropsychologic assessments. Neurologic examinations were performed by a single investigator (M. B. H.) who was unaware of treatment group assignment during the four testing periods: preoperative, within 72 hours before the operation; postoperative, inhospital days 1 to 3 and 7 to 10 ; and long-term, 4 to 6 weeks. Neurologic assessment included an evaluation of mental status, motor and sensory function of cranial nerves II through XII and of the upper and lower extremities, hand coordination, deep tendon reflexes, and primitive reflexes. Any new perioperative central neurologic deficits were diagnosed by fulfillment of any of the following criteria: (1) altered level of consciousness or confusion (not attributable to pharmacologic or metabolic causes), (2) impaired speech, (3) visual disturbances, or (4) new or worsened motor or sensory deficits of the face or upper and lower extremities (not attributable to peripheral lesions). The preoperative neurologic evaluation served as the baseline for this determination.

Neuropsychologic testing was conducted for $109 \mathrm{pa}-$ tients who consented to undergo cognitive function testing in addition to neurologic evaluation. Preoperative neuropsychologic testing was performed within 72 hours before the operation, postoperative testing was performed in the hospital at 7 to 10 days after the operation, and long-term testing was performed at 4 to 6 weeks. The following battery of five tests was used: (1) Mental control test, (2) associate learning test (both tests 1 and 2 are subtests of the Wechsler Memory Scale [WMS]), ${ }^{20}$ (3) digit span test, (4) digit symbol test (both tests 3 and 4 are subtests of the Wechsler Adult Intelligence Scale, Revised [WAIS-R]), ${ }^{21}$ and (5) grooved pegboard test. These tests were selected because of their sensitivity to the neurologic deficits that occur in the cerebral domains most vulnerable to injury after cardiac operations: concentration and attention, auditory memory and new learning ability, immediate auditory memory span, psychomotor function, fine motor dexterity, and tracking. All neuropsychologic tests were administered and scored according to standard procedures by one of two investigators (M. B. H., P. A. B.) who remained unaware of treatment group assignment.

To further evaluate the effect of CPB temperature management strategy on perioperative neuropsychologic performance, the number of patients in each treatment group with either improvement or decrement in any neuropsychologic test score was noted. A postoperative change was considered significant if the difference in score for a given test exceeded the preoperative standard deviation for that test.

Statistical methods. All data were collected on standardized forms, entered into a computerized database, and analyzed with BMDP Software (Los Angeles, Calif.). Results are reported as means ( \pm the standard deviation) or proportions. Continuous measures were compared with unpaired $t$ tests, and categoric measures were compared by $\chi^{2}$ statistical analyses or Fisher's Exact Test as appropriate. Repeated measures were analyzed with two-way analysis of variance. A $p$ value lower than 0.05 was considered to indicate statistical significance.

\section{Results}

The study protocol was completed for all 138 patients. Preoperative patient characteristics in the two treatment groups are shown in Table I. The normothermic group had significantly higher mean age $(p=0.03)$ despite similar percentages of patients older than 60 years in the two treatment groups $(p=0.21)$, and the hypothermic group tended to have a higher prevalence of previous stroke $(p=0.10)$. Of the intraoperative variables (Table II), only glucose concentration during CPB 
differed significantly between the treatment groups $(p<0.001)$; it was higher in normothermic patients despite similar rates of insulin administration during $\mathrm{CPB}$ in the two treatment groups. The retrograde infusion of cardioplegic solution was interrupted to facilitate the placement of the distal coronary anastomoses in fewer than $10 \%$ of the patients in the normothermic group.

Neurologic outcomes. Seven of 138 patients were found to have a new perioperative central neurologic deficit (hypothermic group $n=0$, normothermic group $n=7, p=0.006$ ). Six of these seven patients had nonfatal focal lesions consistent with a central neurologic deficit, and the seventh patient failed to regain consciousness and died on postoperative day 2 of a cerebral infarction.

Neuropsychologic outcomes. One hundred nine patients participated in neuropsychologic evaluation. Results are provided in Table III. There was a significant change in test performance on all the neuropsychologic tests with time $(p<0.001$ for all five tests), but the change was not specific to treatment group. There was a trend toward a group effect in the digit $\operatorname{span}(p=0.07)$ and mental control $(p=$ $0.06)$ tests, however, with the hypothermic group tending to perform better on these two tests with time. Scores on the associate learning (WMS), mental control (WMS), digit symbol (WAIS-R), and grooved pegboard tests deteriorated similarly in the immediate postoperative period in the two treatment groups; however, there was a greater decrement in performance on the digit span test (WAIS-R) in the normothermic group (Table III). At the 4- to 6-week follow-up, all group test scores had returned to preoperative values (associate learning [WMS] and mental control [WMS]) or significantly improved (digit span and symbol [WAIS-R], and grooved pegboard) in both treatment groups.

Many patients were unwilling to complete all the postoperative and follow-up neuropsychologic tests, but there was no difference in the number of patients in each group completing specific tests. Six of the seven patients found to have a central neurologic deficit underwent neuropsychologic testing before discharge from the hospital, and four completed the 4- to 6-week follow-up tests. Because exclusion of the data from these seven patients did not affect the analysis of the neuropsychologic outcome data, these data were included in this study set.

The numbers of patients with improvement or decrement in neuropsychologic test scores did not
Table I. Patient demographics

\begin{tabular}{lccc}
\hline \multicolumn{1}{c}{ Variable } & $\begin{array}{c}\text { Hypothermic } \\
\text { group } \\
(n=70)\end{array}$ & $\begin{array}{c}\text { Normothermic } \\
\text { group } \\
(n=68)\end{array}$ & $p$ \\
\hline Age (yr)* & $61 \pm 11$ & $65 \pm 10$ & 0.03 \\
Age $>60$ yr (\%) & 56 & 68 & 0.21 \\
Gender (\% female) & 19 & 25 & 0.47 \\
Previous stroke (\%) & 12 & 3 & 0.10 \\
Diabetes (\%) & 27 & 24 & 0.70 \\
Hypertension (\%) & 57 & 59 & 0.84 \\
Previous CABG (\%) & 9 & 13 & 0.54 \\
\hline
\end{tabular}

*Mean \pm standard deviation.

differ between the treatment groups in either of the postoperative testing periods (Table IV). In the immediate postoperative period, more than half of all patients had a significant deterioration in at least one neuropsychologic test score and few patients demonstrated any improvement in performance on any measure. In comparison with their preoperative test performance, at the 4- to 6-week follow-up assessment, $72 \%$ of patients achieved neuropsychologic test scores similar to their preoperative results, $13 \%$ showed significant improvement, and $15 \%$ had a significant deterioration in at least one neuropsychologic test score.

\section{Discussion}

These data support the hypothesis that warming of patients during $\mathrm{CPB}$ to maintain the systemic temperature at $35^{\circ} \mathrm{C}$ or more increases the risk of neurologic deficits after coronary revascularization procedures. In this 138-patient study, seven of 68 patients in the actively warmed group had evidence of a new central neurologic deficit, compared with none of 70 patients who underwent operation with hypothermic $\mathrm{CPB}$. In the light of the overall prevalence of central neurologic deficits in this surgical population between $2.5 \%$ and $5 \%,{ }^{22,23}$ the $10 \%$ incidence of new neurologic dysfunction in the normothermic group is of substantial concern.

In contrast to neurologic outcome, CPB temperature management strategy did not substantially influence performance on postoperative neuropsychologic tests. In the immediate postoperative period, performance deteriorated on at least one neuropsychologic test in more than half of all patients in both treatment groups. During the 4- to 6-week follow-up assessment, performance returned to preoperative levels in most patients, but $15 \%$ continued to manifest deterioration on at least one neuropsychologic test. 
Table II. Intraoperative variables

\begin{tabular}{lccc}
\hline \multicolumn{1}{c}{ Variable } & Hypothermic group & Nomothermic group & $p$ \\
\hline Crossclamp time (min)* & $36 \pm 12(14-69)$ & $37 \pm 14(12-79)$ & 0.48 \\
CPB time (min)* & $86 \pm 26(39-167)$ & $82 \pm 23(35-135)$ & 0.35 \\
Glucose (mg/dl) & $152 \pm 66(88-429)$ & $276 \pm 100(100-546)$ & $<0.001$ \\
Insulin (\%) & 16 & 22 & 0.22 \\
IABP (\%) & 3 & 3 & 1.0 \\
\hline
\end{tabular}

*Mean \pm standard deviation; range in parentheses. LABP, Intraaortic balloon pump.

Table III. Intergroup comparison of neuropsychologic test results

\begin{tabular}{|c|c|c|c|c|c|c|c|c|c|c|c|c|c|c|c|}
\hline \multirow[b]{3}{*}{ Test } & \multicolumn{5}{|c|}{ Preoperative (0 to 3 days) } & \multicolumn{5}{|c|}{ Postoperative day 7 to 10} & \multicolumn{5}{|c|}{ 4- to 6-week follow-up } \\
\hline & \multicolumn{2}{|c|}{ Hypothermic } & \multicolumn{2}{|c|}{ Normothermic } & \multirow[b]{2}{*}{$p$} & \multicolumn{2}{|c|}{ Hypothermic } & \multicolumn{2}{|c|}{ Normothermic } & \multirow[b]{2}{*}{$p$} & \multicolumn{2}{|c|}{ Hypothermic } & \multicolumn{2}{|c|}{ Normothermic } & \multirow[b]{2}{*}{$p$} \\
\hline & Mean & $n$ & Mean & $n$ & & Mean & $n$ & Mean & $n$ & & Mean & $n$ & Mean & $n$ & \\
\hline $\begin{array}{l}\text { Associate learning } \\
\text { (WMS) }\end{array}$ & $12 \pm 4$ & 54 & $12 \pm 3$ & 55 & NS & $8 \pm 3$ & 43 & $9 \pm 3$ & 43 & NS & $12 \pm 4$ & 39 & $12 \pm 4$ & 45 & NS \\
\hline $\begin{array}{l}\text { Mental control } \\
\text { (WMS) }\end{array}$ & $6 \pm 2$ & 54 & $6 \pm 2$ & 55 & NS & & 47 & $5 \pm 2$ & 45 & NS & $7 \pm 2$ & 39 & $6 \pm 2$ & 45 & NS \\
\hline $\begin{array}{l}\text { Digit span } \\
\text { (WAIS-R) }\end{array}$ & $14 \pm 4$ & 54 & $13 \pm 4$ & 55 & NS & $14 \pm 4$ & 47 & $12 \pm 3$ & 45 & 0.001 & $16 \pm 5$ & 39 & $14 \pm 4$ & 45 & 0.1 \\
\hline $\begin{array}{l}\text { Digit symbol } \\
\text { (WAIS-R) }\end{array}$ & $36 \pm 12$ & 51 & $31 \pm 13$ & 55 & NS & $30 \pm 13$ & 43 & $25 \pm 14$ & 45 & NS & $41 \pm 13$ & 37 & $35 \pm 15$ & 45 & NS \\
\hline Grooved pegboard & $133 \pm 43$ & 51 & $138 \pm 53$ & 54 & NS & $147 \pm 50$ & 41 & $162 \pm 62$ & 44 & NS & $122 \pm 46$ & 38 & $129 \pm 48$ & 44 & NS \\
\hline
\end{tabular}

All values reported as mean \pm standard deviation. With the exception of the grooved pegboard test results, higher scores indicate better performance. $N S$, Not significant.

Table IV. Number of patients in each group with no change, significant improvement, or significant decrement in neuropsychologic test scores with time

\begin{tabular}{|c|c|c|c|c|c|c|c|c|c|c|c|c|}
\hline \multirow[b]{3}{*}{ Testing period } & \multicolumn{6}{|c|}{ Before operation to POD $7-10$} & \multicolumn{6}{|c|}{ Before operation to 1-month follow-up } \\
\hline & \multicolumn{2}{|c|}{ No change } & \multicolumn{2}{|c|}{ Improvement } & \multicolumn{2}{|c|}{ Decrement } & \multicolumn{2}{|c|}{ No change } & \multicolumn{2}{|c|}{ Improvement } & \multicolumn{2}{|c|}{ Decrement } \\
\hline & $H$ & $N$ & $H$ & $N$ & $H$ & $N$ & $H$ & $N$ & $H$ & $N$ & $H$ & $N$ \\
\hline Associate learning (WMS) & 19 & 22 & 1 & 0 & 23 & 21 & 32 & 36 & 4 & 5 & 3 & 4 \\
\hline Mental control (WMS) & 35 & 40 & 2 & 2 & 10 & 3 & 33 & 36 & 4 & 7 & 2 & 2 \\
\hline Digit span (WAIS-R) & 33 & 39 & 6 & 4 & 8 & 2 & 33 & 38 & 1 & 2 & 5 & 5 \\
\hline Digit symbol (WAIS-R) & 39 & 38 & 0 & 0 & 4 & 7 & 36 & 42 & 1 & 3 & 0 & 0 \\
\hline Grooved pegboard & 37 & 38 & 0 & 0 & 4 & 6 & 35 & 37 & 2 & 5 & 1 & 2 \\
\hline Total & 163 & 178 & 9 & 6 & 49 & 39 & 169 & 189 & 12 & 22 & 11 & 13 \\
\hline
\end{tabular}

Performance differences between testing periods were considered significant when the subject's test score fluctuated more than one preoperative group standard deviation for that test. No significant difference between the two treatment groups was detected in any test for either postoperative testing period. $P O D$, Postoperative day; $N S$, not significant.

During cardiac operations and $\mathrm{CPB}$, the brain is subjected to an almost continuous shower of both macroemboli $(>200 \mu \mathrm{m})$ and microemboli. Atherosclerotic plaques, blood thrombi, platelet aggregates, fat globules, inorganic debris from the CPB circuit, and air and anesthetic gases form both large and small emboli that may result in temporary cerebral ischemia or infarction. Cerebrovascular macroembolization, especially atheroembolism, is believed to be responsible for gross and focal neurologic deficits after cardiac operations ${ }^{24,25}$ - postmortem review of brains from 129 patients who died after cardiac surgical procedures demonstrated a significantly higher prevalence of stroke before death among patients with evidence of atheroemboli $(51 \%)$ than among those without evidence of atheroemboli $(18 \%))^{25}$ The clinical effects of microembolization may go unnoticed, may be seen as a diffuse pattern of neurologic injury, or may contribute to the neuropsychologic dysfunction observed after CPB. ${ }^{26,27}$ Specifically, the severity of postoperative neuropsychologic deficits appears to correlate well with the number of microemboli observed with ultrasonography. ${ }^{26,27}$ The precise etiology of 
neuropsychologic dysfunction in cardiac surgical patients is unknown, however; cerebral inflammation, perioperative medications and a myriad of other factors may influence performance on neuropsychologic examinations.

Swain ${ }^{2}$ characterized the use of hypothermia during CPB as "the current mainstay of cerebral protection," and substantial evidence demonstrates the cerebral protective effects of hypothermia during temporary focal or global cerebral ischemia. ${ }^{12-14,18,28-31}$ Hypothermia reduces cellular metabolism, which limits energy substrate and oxygen consumption, thereby increasing cellular tolerance to diminished blood flow and oxygen delivery. ${ }^{32}$ In addition, hypothermia ameliorates the ischemia-induced increase in excitotoxic neurotransmitters (most notably glutamate) that amplify ischemic damage after cell failure to produce high-energy triphosphates. ${ }^{33}$ In a nonbypass animal model of temporary ischemia, Busto and colleagues ${ }^{28}$ demonstrated that maintaining brain temperature at $30^{\circ}$ to $33^{\circ} \mathrm{C}$ completely inhibited the release of glutamate and significantly attenuated the release of dopamine. Even small decrements in cerebral temperature thus confer protection. Finally, hypothermia also reduces the cellular acidosis that accompanies ischemia ${ }^{13}$ and has a palliative effect on the development of edema, possibly by maintaining the integrity of the blood-brain barrier. ${ }^{34}$

The protective effects of hypothermia are less clear for the permanent lesions (such as aortic atheroma) that are probably responsible for much of the cerebral ischemia accompanying cardiac operations. ${ }^{19,31,35}$ Ridenour and coworkers ${ }^{31}$ reported that mild hypothermia $\left(33^{\circ} \mathrm{C}\right)$ did not reduce the volume of cerebral infarction in rats with a permanent focal lesion, whereas Onesti and associates ${ }^{35}$ demonstrated that deep hypothermia $\left(24^{\circ} \mathrm{C}\right)$ effectively limited cerebral infarction in a similar model. Morikawa and colleagues ${ }^{18}$ found that manipulations of brain temperature had a greater effect in rats subjected to reversible ischemic lesions but also found that even moderate hypothermia $\left(30^{\circ} \mathrm{C}\right)$ tended to reduce cerebral infarct volume in rats with permanent Jesions. On the basis of these animal data, our use of a hypothermic CPB technique $\left(28^{\circ} \mathrm{C}\right)$ may have provided protection from both temporary and permanent ischemic insults.

Several studies suggest that manipulation of the aorta is associated with embolization of atheromatous material to the cerebral circulation. ${ }^{24}$ In this study, both treatment groups had similar systemic temperatures $\left(35^{\circ} \mathrm{C}\right.$ to $\left.37^{\circ} \mathrm{C}\right)$ at the time of maximum aortic manipulation (during the application of the crossclamp), suggesting that the absence of neurologic deficits in the hypothermic group might not be related to the temperature of the patient after crossclamp application. The institution of hypothermia after an ischemic insult, however, also may be protective. $^{36,37}$ Zhang and colleagues ${ }^{37}$ demonstrated that perfusion with hypothermic blood $\left(30^{\circ} \mathrm{C}\right)$ after a 2-hour normothermic ischemic insult reduced cerebral infarction volume in a rat model of temporary cerebral ischemia.

It is unclear why hypothermia did not limit the neuropsychologic dysfunction identified in the patients managed with $\mathrm{CPB}$ at $28^{\circ} \mathrm{C}$. Although cerebral emboli resulting in vascular occlusion and ischemia are thought to be a possible cause of neuropsychologic deficits in patients undergoing cardiac operations, other mechanisms, such as changes in cerebral microcirculation and coagulation, may contribute to postoperative neuropsychologic dysfunction. For example, cerebral air emboli damage pial vessel endothelium, leading to the disruption of vasoreactivity and ultrastructural abnormalities. ${ }^{38}$ Even in the absence of mechanical blockage of the microvasculature, air emboli can disrupt normal cerebral microcirculation. One could speculate that the changes induced by air microemboli may contribute to the neuropsychologic dysfunction observed after CPB. These microvascular processes may not be influenced by temperature in the same manner as ischemic phenomena initiated by the mechanical obstruction of the cerebral microcirculation. In summary, the processes responsible for gross neurologic deficits after cardiac operations probably differ from those causing neuropsychologic dysfunction and may be affected by temperature in a different manner.

Factors that may have contributed to our finding of increased risk of adverse neurologic outcome in our normothermically managed patients include age, criteria for inclusion and for risk, and a rigorously controlled study protocol. The risk of adverse neurologic outcomes increases with age, ${ }^{39}$ and aspects of the different modes of delivery of cardioplegic solution may have increased the embolic load to the brain. Additionally, patients who were actively warmed during CPB were exposed to higher blood concentrations of glucose than patients cooled to $28^{\circ} \mathrm{C}$, and several animal studies suggest that hyperglycemia exacerbates both global and focal neurologic ischemic injury. ${ }^{40,41}$ That is, the anaerobic 
metabolism of glucose potentiates the excitotoxic cascade that causes neurologic injury. ${ }^{42}$ Mild $\left(32^{\circ}\right.$ to $\left.33^{\circ} \mathrm{C}\right)$ and moderate hypothermia $\left(30^{\circ} \mathrm{C}\right)$ limit both the neurologic and histologic manifestations of hyperglycemia in neuronal ischemia ${ }^{43,44}$ and studies in patients undergoing hypothermic CPB suggest that hyperglycemia during CPB does not worsen neurologic injury after cardiac operations. ${ }^{45} \mathrm{Al}$ though McLean and coworkers ${ }^{11}$ also noted significantly higher blood glucose concentrations in their "warmed" patients without increased risk of stroke, their failure to control for "drift" (the spontaneous loss of body heat during $\mathrm{CPB}$ ) in the tested temperature range precludes their ability to find any reliable associations among hyperglycemia, normothermia, and outcome. Perhaps the increased prevalence of neurologic deficits found in our normothermic group was not the result of temperature management strategy but rather of the hyperglycemic milieu present during a period (CPB) when a cerebral ischemic insult was likely. Alternatively, normothermic, hyperglycemic conditions during CPB may have had an additive or synergistic adverse effect on neurologic outcome in the normothermic treatment group.

Because we actively warmed our normothermic patients to maintain a bladder temperature between $35^{\circ}$ and $37^{\circ} \mathrm{C}$, it is possible that many if not all had cerebral temperatures that were not normothermic but were in fact hyperthermic $\left(>37^{\circ} \mathrm{C}\right)$. The $\mathrm{CPB}$ circuit water bath was maintained at $39^{\circ}$ to $40^{\circ} \mathrm{C}$, so the blood infused into the aortic root may have had a temperature greater than $37^{\circ} \mathrm{C}$. Several animal studies demonstrate that even small $\left(2^{\circ} \mathrm{C}\right)$ increases in brain temperature can exacerbate neuronal injury. Dietrich and associates ${ }^{16}$ demonstrated that the histopathologic consequences of temporary global forebrain ischemia were significantly worse in rats maintained at $39^{\circ} \mathrm{C}$ than in those maintained at $37^{\circ} \mathrm{C}$; they subsequently found that mild intraischemic hyperthermia $\left(39^{\circ} \mathrm{C}\right)$ exacerbated pathologic changes in blood-brain barrier permeability. ${ }^{34} \mathrm{Sim}$ ilarly, Mitani and Kataoka ${ }^{17}$ found that increasing cerebral temperatures in gerbils from $37^{\circ} \mathrm{C}$ to $39^{\circ} \mathrm{C}$ during temporary global ischemia significantly increased both postischemic release of glutamate and mortality. Our study results thus may not suggest that hypothermia per se protects against ischemic cerebral injury during CPB as much that hyperthermia potentiates ischemic pathologic processes in the brain during cardiac operations.

Comparison with other studies. Several studies have reported on neurologic outcomes in patients undergoing cardiac procedures with varying types of normothermic temperature management strategies during CPB. ${ }^{6,8,10,11}$ Our results are consistent with those obtained by Martin and associates ${ }^{8}$ in their study of hypothermic versus normothermic technique in a group of 1001 patients, of which our 138 patients form a specific subset. Although preoperative and postoperative neurologic examinations were not performed in the series of Martin and associates ${ }^{8}$ (limiting the ability to detect postoperative adverse neurologic events), the normothermic technique increased the risk for adverse neurologic outcomes $(4.5 \%$ versus $1.4 \%$ in the hypothermic group). Importantly, only three of the seven adverse neurologic events identified in this study's population were discovered by the chart review methods used by Martin and associates. ${ }^{8}$ Additionally, all patients found by Martin and associates ${ }^{8}$ to have a postoperative adverse neurologic event were similarly identified in this study. Sotaniemi, Juolasmaa, and Hokkanen ${ }^{46}$ reported that study methods that depend on retrospective chart review to identify clinical events grossly underestimate the prevalence of postoperative adverse neurologic events.

Our results do not reflect those reported by Singh and colleagues, ${ }^{6}$ the WHI, ${ }^{10}$ or McLean and coworkers. ${ }^{11}$ Of these three groups of investigators, only Singh and colleagues ${ }^{6}$ consistently warmed patients during $\mathrm{CPB}$, maintaining the temperature of the bladder at $36^{\circ} \mathrm{C}$ and that of the perfusate at $37^{\circ} \mathrm{C}$. Myocardial protection was provided by hypothermic cardioplegic solution and iced saline solution slush in the pericardial sac. It is possible that this protection technique reduced the local temperature of the blood pumped through the aorta and to the cerebral circulation, thereby limiting the brain's exposure to normothermic blood temperatures. Their finding of surprisingly few strokes $(1 \%)$ in a population undergoing open-chamber and closedchamber cardiac procedures may also reflect a failure to perform preoperative neurologic assessments. Without a baseline assessment, the extent of neurologic dysfunction would be difficult to quantify.

The WHI ${ }^{10}$ and McLean and coworkers ${ }^{11}$ (studying a subgroup from the WHI study) both reported that normothermic CPB does not increase the risk of adverse neurologic events in patients undergoing coronary artery bypass grafting. The respective prevalences of stroke in the normothermic and hypothermic groups were $1.6 \%$ and $1.5 \%$ in the WHI trial ${ }^{10}$ and $2.6 \%$ and $5.2 \%$ in the study of McLean and coworkers. ${ }^{11}$ There are, however, sev- 
eral important differences between those studies and this one. Most important, neither the $\mathrm{WHI}^{10}$ nor McLean and coworkers ${ }^{11}$ were consistent in studying a single temperature management strategy. Some patients were actively warmed to $37^{\circ} \mathrm{C}$, but others were allowed to "drift" to systemic temperatures of $33^{\circ}$ to $36^{\circ} \mathrm{C}$. Second, also unlike this study, patients with an increased risk of a perioperative adverse neurologic event (patients with a preoperative history of carotid stenosis or stroke) were not included in either previous study. Yet patients with symptomatic cerebrovascular disease have an increased risk of perioperative stroke. ${ }^{47,48}$ Third, the mean ages of patients in the studies of the $\mathrm{WHI}^{10}$ and McLean and coworkers ${ }^{11}$ were substantially lower (about 58 years) than that of our patients (about 63 years), and advanced age has been reported to increase the risk of adverse neurologic outcome for patients undergoing coronary operations. ${ }^{39}$ Fourth, in contrast to the practice of the WHI group, ${ }^{10}$ in this study a partially occluding aortic clamp was placed in most patients to facilitate the placement of the proximal coronary artery vein grafts. This manipulation may have increased the embolic load to the brain. Perhaps patients in the hypothermic group tolerated this additional insult, whereas those in the normothermic group were unprotected by reduced cerebral temperatures. Finally, the WHI group ${ }^{10}$ became aware of the finding of Martin and associates ${ }^{8}$ of an association between normothermic $\mathrm{CPB}$ and adverse neurologic events in the midst of their study, and they immediately terminated their active warming protocol to avoid patient risk. Although these differences make it difficult to compare our results with those of these investigators, it may be reasonable to suggest that overall their patients were at less risk for a perioperative neurologic deficit because of less conducive preoperative demographic characteristics and a tendency toward lower cerebral temperatures during $\mathrm{CPB}$.

Because the brain is vulnerable to ischemic injury during cardiac surgery and $\mathrm{CPB}$, clinicians must carefully consider the factors that can limit or potentiate the pathophysiologic processes that result in cerebral damage. In this study, patients in the normothermic group may have been exposed to arterial blood with a temperature in excess of $37^{\circ} \mathrm{C}$. This phenomenon could be expected to increase the risk of adverse neurologic outcome. Although normothermic myocardial protection techniques may be desirable in certain patient groups, the CPB technique should not expose the brain to an unnec- essary temperature or heat load. This study demonstrates that patients undergoing coronary revascularization should not be actively warmed during $\mathrm{CPB}$ to maintain bladder temperatures between $35^{\circ}$ and $37^{\circ} \mathrm{C}$ because that technique increases the risk of stroke in this group of patients. Several investigators are now studying the effect of "tepid" or "lukewarm" CPB temperature management on myocardial outcomes. Perhaps these and future studies will define the optimal temperature management strategy to protect both the heart and the brain during cardiac operations.

We thank Anthony Y. Stringer, $\mathrm{PhD}$, and Patricia A. Bryant, BS, for their assistance in scoring and administering the neuropsychologic tests, Diane Beatty for typing the manuscript, and Winifred von Ehrenburg for her editorial assistance.

\section{REFERENCES}

1. Bigelow WG, Lindsay WK, Greenwood WF. Hypothermia: its possible role in cardiac surgery. Ann Surg 1950;132:84966.

2. Swain JA. Cardiac surgery and the brain. N Engl J Med 1993;329:1119-20.

3. Lichenstein SV, Abel JG. Warm heart surgery: theory and current practice. Chicago: Mosby-Year Book, 1992:135-54.

4. Christakis GT, Koch JP, Deemar KA, Fremes SE, Sinclair L, Chen E, et al. A randomized study of the systemic effects of warm heart surgery. Ann Thorac Surg 1992;54:449-59.

5. Gundry SR, Wang N, Bannon D, Vigesaa RE, Eke C, Pain S, et al. Retrograde continuous warm blood cardioplegia: maintenance of myocardial homeostasis in humans. Ann Thorac Surg 1993;55:358-63.

6. Singh AK, Feng WC, Bert AA, Rostenberg FA. Warm body, cold heart surgery: clinical experience in 2817 patients. Eur $\mathrm{J}$ Cardiothorac Surg 1993; 7:225-30.

7. Roe BB. Warm blood cardioplegia: back to square one. Ann Thorac Surg 1993;55:330-1.

8. Martin TC, Craver JM, Gott JP, Weintraub WS, Ramsay J, Mora $\mathrm{CT}$, ef a1. Prospective, randomized trial of retrograde warm-blood cardioplegia: myocardial benefit and neurologic threat. Ann Thorac Surg 1994;57:298-304.

9. Vaughn CC, Opie JC, Florendo FT, Lowell PA, J Austin. Warm blood cardioplegia. Ann Thorac Surg 1993;55:1227-32.

10. Warm Heart Investigators. Randomised trial of normothermic versus hypothermic coronary bypass surgery. Lancet 1994;343:559-63.

11. McLean RF, Wong BI, Naylor CD, Snow WG, Harrington EM, Gawel M, et al. Cardiopulmonary bypass, temperature, and central nervous system dysfunction. Circulation 1994; 90(5 Pt 2):II250-5.

12. Churn SB, Taft WC, Billingsley MS, Blair RE, DeLorenzo RJ. Temperature modulation of ischemic neuronal death and inhibition of calcium/calmodulin-dependent protein kinase II in gerbils. Stroke 1990;21:1715-21.

13. Chopp M, Knight R, Tidwell CD, Helpern JA, Brown E, Welch KM. The metabolic effects of mild hypothermia on global cerebral ischemia and recirculation in the cat: com- 
parison to normothermic and hyperthermia. $\mathrm{J}$ Cereb Blood Flow Metab 1989;9:141-8.

14. Minamisawa $\mathrm{H}$, Nordstrom $\mathrm{CH}$, Smith ML, Siesjo BK. The influence of mild body and brain hypothermia on ischemic brain damage. J Cereb Blood Flow Metab 1990;10:365-74.

15. Kuroiwa T, Bonnekoh P, Hossmann KA. Prevention of postischemic hyperthermia prevents ischemic injury of $\mathrm{CA} 1$ neurons in gerbils. J Cereb Blood Flow Metab 1990;10:550-6.

16. Dietrich WD, Busto R, Valdes I, Loor Y. Effects of normothermic versus mild hyperthermic forebrain ischemia in rats. Stroke 1990;21:1318-25.

17. Mitani A, Kataoka K. Critical levels of extracellular glutamate mediating gerbil hippocampal delayed neuronal death during hypothermia: brain microdialysis study. Neuroscience 1991;42:661-70.

18. Morikawa E, Ginsberg MD, Dietrich WD, Duncan RC, Kraydieh S, Globus MY, et al. The significance of brain temperature in focal cerebral ischemia: histopathological consequences of middle cerebral artery occlusion in rat. J Cereb Blood Flow Metab 1992;12:380-9.

19. Chopp M, Welch KM, Tidwell CD, Knight R, Helpern JA. Effect of mild hyperthermia on recovery of metabolic function after global cerebral ischemia in cats. Stroke 1988;19: $1521-5$.

20. Wechsler D. Wechsler adult intelligence scale manual. New York: New York Psychological Corporation, 1955.

21. Wechsler D. Wechsler adult intelligence scale, revised (WAISR). New York: New York Psychological Corporation, 1981.

22. Mora CT, Murkin JM. The central nervous system: responses to cardiopulmonary bypass. In: Mora CT, editor. Cardiopulmonary bypass: principles and techniques of extracorporeal circulation. New York: Springer-Verlag, 1995:114-46.

23. Gardner TJ, Horneffer PJ, Manolio TA, Pearson TA, Gott VL, Baumgartner WA, et al. Stroke following coronary artery bypass grafting: a ten-year study. Ann Thorac Surg 1985;40: 574-81.

24. Wareing TH, Davila-Roman VG, Barzilai B, Murphy SF, Kouchoukos NT. Management of the severely atherosclerotic ascending aorta during cardiac operations: a strategy for detection and treatment. J Thorac Cardiovasc Surg 1992;103: 453-62.

25. Blauth C, Cosgrove DM, Webb BW, Ratcliff NB, Boylan M, Piedmonte MR, et al. Atheroembolism from the ascending aorta: an emerging problem in cardiac surgery. $\mathbf{J}$ Thorac Cardiovasc Surg 1992;103:1104-12.

26. Clark RE, Brillman J, Davis DA, Lovell MR, Price TR, Magovern GT. Microemboli during coronary artery bypass grafting: genesis and effect on outcome. J Thorac Cardiovasc Surg 1995;109:249-58.

27. Pugsley W, Klinger L, Paschalis C, Aspey B, Newman S, Harrison UT, et al. Microemboli and cerebral impairment during cardiac surgery. Vasc Surg 1990;22:34-43.

28. Busto R, Globus MY, Dietrich WD, Martinez E, Valdés I, Ginsberg MD. Effect of mild hypothermia on ischemiainduced release of neurotransmitters and free fatty acids in rat brain. Stroke 1989;20:904-10.

29. Illievich UM, Zornow MH, Choi KT, Strnat AM, Scheller MS. Effects of hypothermia or anesthetics on hippocampal glutamate and glycine concentrations after repeated transient global cerebral ischemia. Anesthesiology 1994;80:177-86.

30. Leonov Y, Sterz F, Safar P, Radovsky A, Oku K, Tisherman $\mathrm{S}$, et al. Mild cerebral hypothermia during after cardiac arrest improves neurological outcome in dogs. J Cereb Blood Flow Metab 1990;10:57-70.

31. Ridenour TR, Warner DS, Todd MM, McAllister AC. Mild hypothermia reduces infarct size resulting from temporary but not permanent focal ischemia in rats. Stroke 1992;23: 733-8.

32. Michenfelder JD. The hypothermic brain. In: Anesthesia and the brain. Michenfelder JD, editor. New York: Churchill Livingstone, 1988:23-34.

33. Choi DW, Maulucci-Gedde M, Kriegstein AR. Glutamate neurotoxicity in cortical cell culture. J Neurosci 1987;7:357-68.

34. Dietrich WD, Busto R, Halley M, Valdes I. The importance of brain temperature in alterations of the blood brain barrier following cerebral ischemia. J Neuropathol Exp Neurol 1990; 49:486-97.

35. Onesti S, Barker CJ, Sun PP, Solomon RA. Transient hypothermia reduces ischemic brain injury in the rat. Neurosurgery 1991;29:369-73.

36. Kuluz JW, Gregory GA, Yu ACH, Chang Y. Selective brain cooling during and after prolonged global ischemia reduces cortical damage in rats. Stroke 1992;23:1792-7.

37. Zhang RL, Chopp M, Chen H, Garcia JH, Zhang ZG. Postischemic (1 hour) hypothermia significantly reduces ischemic cell damage in rats subjected to 2 hours of middle cerebral artery occlusion. Stroke 1993;24:1235-40.

38. Persson LI, Johansson BB, Hansson. Ultrastructural studies on blood-brain barrier dysfunction after cerebral air embolism in the rat. Acta Neuropathol 1978;44:53-9.

39. Tuman KJ, McCarthy RJ, Najafi H, Ivankovich AD. Differential effects of advanced age on neurologic and cardiac risks of coronary artery operations. J Thorac Cardiovasc Surg $1992 ; 104: 1510-7$

40. Nakakimura K, Fleischer JE, Drummond JC, Scheller MS, Zornow MH, Grafe MR, et al. Glucose administration before cardiac arrest worsens neurologic outcome in cats. Anesthesiology 1990;72:1005-11.

41. Lam AM, Winn HR, Cullen BF, Sundling N. Hyperglycemia and neurological outcome in patients with head injury. $\mathbf{J}$ Neurosurg 1991;75:545-51.

42. Siesjo BK, Bengtsson F. Calcium fluxes, calcium antagonists, and calcium-related pathology in brain ischemia hypoglycemia, and spreading depression: a unifying hypothesis. J Cereb Blood Flow Metab 1989;9:127-40.

43. Lundgren J, Smith ML, Siesjo BK. Influence of moderate hypothermia on ischemic brain damage incurred under hyperglycemic conditions. Exp Brain Res 1991;84:91-101.

44. Dietrich WD, Alonso O, Busto R. Moderate hyperglycemia worsens acute blood-brain barrier injury after forebrain ischemia in rats. Stroke 1993;24:111-6.

45. Metz S, Keats AS. Benefits of a glucose-containing priming solution for cardiopulmonary bypass. Anesth Analg 1991;72: 428-34.

46. Sotaniemi KA, Juolasmaa A, Hokkanen ET. Cerebral outcome after extracorporeal circulation: comparison between prospective and retrospective evaluations. Arch Neurol 1981; 40:75-7.

47. Martin WR, Hashimoto SA. Stroke in coronary bypass surgery. Can J Neurol Sci 1982;9:21-6.

48. Jones EL, Craver JM, Michalik RA, Murphy DA, Guyton RA, Bone DK, et al. Combined carotid and coronary operations: when are they necessary? J Thorac Cardiovasc Surg 1984;87:7-16. 